\title{
An English Reconquista: The Impact of the Enhanced Language Proficiency Requirements on Canada's Multicultural Immigration Model
}

\author{
Anna Schemmel \\ University of Richmond \\ afschemmel@gmail.com \\ Patricia B. Strait \\ University of Richmond \\ pstrait@richmond.edu
}

Doi:10.5901/mjss.2013.v4n10p87

\begin{abstract}
The multicultural model of immigration advocates for a blended society, where individuals are respected and cultural, religious and linguistic diversity is celebrated. However; in Canada which has long been an advocate for the multicultural immigration model, a feeling of resentment has recently surfaced toward some immigrant groups who are perceived as a threat to Canadian culture and values. This preliminary study explores the potential outcomes of the newly enhanced English language proficiency requirements on Canada's multicultural immigration model. Historically, the majority of immigrants in Canada have entered through the Federal Skilled Worker Program which uses a point system to determine entrance eligibility. In 2012, however, the language proficiency requirement for this program was made significantly more rigorous, necessitating all applicants to demonstrate a a enhanced level of proficiency in either English or French. Applicants under the newly enhanced Federal Skilled Worker program must now meet a minimum score in language as well as score the minimum number of required points in education, work experience and adaptability as set forth by the Minister. This essay explores the potential outcomes of the new more stringent language requirement and its potential influence on Canada's multicultural immigration model.
\end{abstract}

Keywords: immigration, language proficiency, Canada, multiculturalism

\section{Introduction}

While some European countries have proclaimed multiculturalism a failure, Canada has remained committed to multiculturalism as their preferred immigration model (Rodriguez-Garcia, 2010). The multicultural model of immigration advocates for a blended society, where individuals are respected and cultural, religious and linguistic diversity is celebrated (Rodriguez-Garcia, 2010). According to Strait (2012, p. 12), "Multiculturalists believe that immigrants should not be forced to fully assimilate or integrate with the host population but rather host countries should encourage and foster a pluralistic society". An authentic multicultural model embraces diversity at an institutional level by sanctioning religious freedom and the support of the first languages of immigrants (Rodriguez-Garcia, 2010). Canadians consider themselves tolerant of different cultures. Recently, however, there has been increasing resentment towards some immigrant groups based on the perceived threat they present to Canadian culture and values. (Li, 2001).

According to Kymlicka (2012), "Canada was the first Western country to officially adopt a multiculturalism policy toward immigrant ethnic groups, and it remains the only country in which multiculturalism is enshrined in the constitution" (p. 10). In addition, the Canadian government sponsors a variety of programs such as Black History Month, Asian Heritage month, diversity resources for teachers, and the annual Paul Yuzyk Award for Multiculturalism. These programs are designed to celebrate the different immigrant groups within Canada. Support for diversity is prevalent in government initiatives at both the local and national level. According to the Annual Report on the Operation of Canadian Multiculturalism Act 2010- 2011, "the Canadian approach to diversity has encouraged the evolution of a dynamic, successful and highly diverse society" (Citizenship and Immigration Canada, 2012b). The Canadian government contends that Canadians who are able to speak a variety of languages make it easier for Canada to compete globally (Citizenship and Immigration Canada, 2012d). Additionally, Canadians assert that their commitment to multiculturalism is one of the reasons that Canada is a preferred destination for immigrants (ibid). 
Despite these policies, many immigrants have faced challenges finding their way in the Canadian economy thereby raising concerns among Canadian citizens (Friesen, 2012b). In response to these growing concerns, the Canadian government revised the application process effective July 1, 2012 for individuals wishing to enter Canada through the Federal Skilled Worker program (Friesen, 2012a). According to narrative on the Application for Permanent Residence, "Skilled workers are selected as permanent residents based on their education, work experience, knowledge of English and/or French, and other criteria that have been shown to help them become economically established in Canada" (Citizenship and Immigration Canada, 2012a). Arguing that language proficiency is essential for integration, the Canadian government now requires that immigrants must demonstrate fluency in English or French in order to be eligible for citizenship (Citizen and Immigration Canada, 2012b).

This essay explores the implications of this more stringent language requirement on the policy of multiculturalism promoted by the Canadian government. Specifically, this essay examines the motivations behind the new Canadian requirements, and what consequences those requirements may have on their multicultural model of immigration. Although immigrants applying to Canada have the option to demonstrate proficiency in English or French, this essay will focus solely on the English proficiency requirement and its potential impacts.

\section{Literature Review}

A commitment to diversity was not always present in Canada. Early immigration policy in Canada was explicitly restrictive. According to the Immigration Act of 1910, "The Governor in Council may prohibit for a stated period, or permanently, the landing in Canada or the landing at any specified port of Canada of immigrants belonging to any race deemed unsuited to the climate or requirements of Canada" (Green\& Green, 2004, p. 106). Prior to World War I, the central goal of Canadian immigration policy was to attract individuals to work on farms and in homes from traditionally white sources such as Great Britain, Ireland, Australia and Western Europe. Strict restrictions on immigration continued when the law was revised in 1919 to include a literacy test, and reinforced the government's control over the "level, timing, and ethnic composition of immigrants" (Green, et al., 2004, p. 108). In 1946, Canada recognized the need for additional immigrants, but maintained their commitment to a selective policy, with a 1947 address to the House from Mackenzie King included this statement warning against immigration of visible minorities, "Canada is perfectly within its rights in selecting persons whom it regards as desirable future citizens...Large scale immigration from the Orient would change the fundamental composition of the Canadian population" (Green, et al., 2004, p. 108).

In 1967, Canada's new immigration policy specified a commitment to diversity and the variable of race was removed from immigration applications (Citizenship and Immigration Canada, 1996). A points system was established for the Federal Skilled Worker Program which allowed the Canadian government to evaluate potential immigrants without discrimination based on race, religion or national origin (Friesen, 2012a). Under the points system, potential immigrants are evaluated based on criteria which include work experience, education, language proficiency, and adaptability. With the new system in place, Canada saw a significant shift in source countries of immigrants. In 1967, 29\% of immigrants were British or Irish, 9\% American, and the remaining top source countries were European. Overtime these source countries have changed, and throughout the past decade, Canada has seen a significant increase in immigrants from Asia. The top three source countries from 2001- 2010 have been the Philippines, China, and India (Citizenship and Immigration Canada, 2010). This increase in diversity has presented some difficult economic and cultural challenges for the host populations of Canada, which has resulted in the new requirement of language proficiency testing for all Federal Skilled Worker applications.

\section{Description of the new language requirement}

A commitment to the official languages of Canada is reinforced through the points system established in the Immigration and Refugee Protection Regulations. According to these regulations, applicants for the Federal Skilled Worker program must meet a minimum score in each of the categories which include language, education, work experience and adaptability. The minimum number of points required in each area may be adjusted based on the number of applications, projections regarding the number of skilled workers who are likely to become permanent residents, and the number of skilled workers already established in Canada (Immigration and Refugee Protection Regulations, 2012).

The Immigration and Refugee Protection Act requires that skilled workers demonstrate proficiency in the official languages through designated organizations or assessments as established by the minister (Immigration and Refugee Protection Regulations, 2012). This requirement is not new. However, the previous assessment of language proficiency 
was more subjective in nature, and individuals were often credited with greater language skills then they actually had. Under new the rules, which apply to all applicants submitting after November 1, 2012, applicants must provide "objective evidence" of language proficiency. This can be demonstrated through results obtained from an approved third party exam which measures proficiency based on the Canadian Language Benchmark Standards (CLB), evidence of secondary or post-secondary education completed in English or French, or evidence of achieving an appropriate level of proficiency through a government funded training program (Citizenship and Immigration Canada, 2012c).Language proficiency includes the ability to speak, listen, read, and write in the designated primary language (English or French), with additional points available for proficiency in the secondary language (English or French). Points are awarded based on the score received on the CLB evaluation. In a September 2012 press release, Citizenship, Immigration and Multiculturalism Minister, Jason Kenney, announced that all citizenship applications for individuals ages 18 - 54 must provide evidence of a minimum CLB level 4 in speaking, listening, reading and writing in order for their application to be considered by immigration services (Citizenship and Immigration Canada, 2012c). The CLB Level 4 is described as the ability to "communicate basic needs and personal experience, follow, with considerable effort, simple formal and informal conversations, read a simple set of instructions, and write short messages, postcards, notes or directions" (Citizenship and Immigration Canada, 2012e, p 6). A sample question requires the applicant to write the following essay: "Describe a favorite memory from a weekend" (CELPIP General, 2012). According to Kenney (Citizenship and Immigration Canada, 2012c, p3),"extensive research has consistently shown that the ability to communicate effectively in either French or English is a key factor in the success of new citizens in Canada".

\section{Motivations behind enforcement of language testing}

The Canadian Multiculturalism Act of 1988 articulates Canada's commitment to multiculturalism and the requirements placed on the federal government to ensure an environment of inclusion for diverse populations. According to the Act, Canadians should "recognize and promote the understanding that Multiculturalism is a fundamental characteristic of the Canadian heritage and identity that provides an invaluable resource in the shaping of Canada's future" (Canadian Multiculturalism Act, 1988, 3b). The Multiculturalism Act also addresses the issue of language diversity stating that Federal Institutions should "make use, as appropriate, of the language skills and cultural understanding of individuals of all cultures; and generally carry on their activities in a manner that is sensitive and responsive to the multicultural reality of Canada" (Canadian Multiculturalism Act, 1988, 2f). The Act recognizes a commitment to the official languages of Canada calling on the population to "preserve and enhance the use of languages other than English and French while strengthening the status and use of the official languages of Canada" (Canadian Multiculturalism Act, 1988, 3i).By requiring evidence of English or French language proficiency, Canada is attempting to foster the economic success of new immigrants. According to Green, et al. (2004, p. 128), "Immigrants fluent in English or French are argued to enter the labor market more quickly and to be more successful in the long run". Despite this perception, data has shown that even a highly educated immigrant typically earns only one half of the salary of their Canadian counterparts after one year in the country. It may take up to ten years for an immigrant to match the earnings of a similarly qualified native born Canadian (Citizenship and Immigration Canada, 2004). Upon arriving in Canada, immigrants are entitled to Canada's social programs which include free health care and language training. These benefits are expensive, and the tax revenues generated from immigrants are not enough to cover the costs of these social programs (Tamburri, 1998). In 1996, 41\% of immigrants spoke neither English nor French, which had a detrimental effect on their earning potential (ibid). The new language requirement has been a source of controversy among Canadians. Some fear that the new language requirement may have a disproportionate impact on visible minorities. Recent media reports indicate that the new language requirement is contributing to a feeling of discrimination and intolerance between the immigrants and the host population. As a recent article suggests, a country's immigration policy by its nature is intended to discriminate against certain groups and the new Canadian requirements "point to a tighter border for certain immigrants" (Black, 2013). Despite the strain placed on the Canadian economy, the majority of Canadians continue to support immigration. Polls also have shown that almost half of Canadians agree that immigrants should have the ability to maintain their cultural and religious practices (Multiculturalism in Canada: one nation or many, 2006). Since the Multiculturalism Act went into effect in 1988, multiculturalism itself has become a basic Canadian value (ibid).

\section{Analysis and Discussion}

Given the information and trends described within the literature review, there appear to be three potential impacts on 
Canada as a result of the new language requirement. These potential impacts include: an increase in the economic benefit derived from immigrants, a shift in the ethnic backgrounds of new immigrants, and an increase in the power and influence of the host population. Each of these potential outcomes is discussed below.

\subsection{Potential outcome one: Economic benefits derived from immigrants in Canada}

One of the major drivers for the language requirement is a desire to ensure the economic success of immigrants in Canada while reducing their need for social programs such as language training. The government funded Language Instruction for Newcomers to Canada (LINC) has increased in cost from \$94 million in 2004 to \$172 million in 2008-2009. These expenses include course instruction as well as transportation and child minding services for participants. From 2008-2009, 55,000 immigrants participated in the program (Citizenship and Immigration Canada, 2011). The assumption is that by requiring all immigrants demonstrate fluency in English or French prior to entry, immigrants will be able to contribute more quickly to the Canadian economy. Canadian officials are hopeful that these same individuals will also have higher earning potential then non-English speaking immigrants and require fewer costly social services. As this essay is a preliminary study of the implications of the language requirement, additional research is needed to verify if these assumptions are correct. If the desired economic benefits are realized, it may be tempting for Canadian policy makers to continue to make immigration policy decisions based on economic factors rather than its commitment to diversity which has been a central part of Canada's multicultural model.

\subsection{Potential outcome two: Change in ethnic background of new immigrants}

By requiring that individuals speak English or French prior to entering Canada, the pool of potential immigrants will dramatically shift to immigrants from English speaking countries. This will likely have a stifling effect on immigrants who come from countries who have a completely different language structure and alphabet system than English. Historically speaking, the Philippines, China and India have been the top three source countries for immigrants to Canada. When the language proficiency requirement is implemented, the numbers of immigrants from Asia might decrease significantly as it becomes necessary for individuals to demonstrate basic fluency in English prior to entering Canada. In the past, when the points system was initially established and race and ethnicity were removed from immigration applications, it was approximately 30 years before Canada saws shift in source countries from traditionally white countries to the majority of immigrants coming from Asia. As the new language requirement takes effect, it is likely that the source countries will once again shift. As Canadian immigration policy becomes more favorable towards English speakers, Canada will pull more from countries where individuals have easy access to English instruction. These potential source countries are also more likely to be more closely aligned with Canada's values and religious practices. In addition, English speaking applicants are more likely to be white, which will reduce the ethnic diversity of new immigrants to Canada. By targeting new immigrant groups who speak English, Canadian policymakers are sanctioning the growing preference for individuals who are similar to the host population of English speaking Canadians in terms of ethnicity, religion and values.

\subsection{Potential outcome three: Increase in the influence and power of host population}

In addition to restricting the diversity of new immigrants accepted by Canada, the new language requirement may also give way to an increase in the power and influence of the Canadian host population. This resurgence of traditional Canadian values could result in the isolation of "visible minority" groups currently living in Canada. Many of these minority groups have voiced their disagreement with the new language proficiency policy, noting that they have been successful in Canada even though they had very little knowledge of English or French. Validated by the new language requirement, the English speaking host population may also begin to dominate the political dialog. The changing social climate may cause minority groups to feel disconnected from Canadian society and values. As the language requirement takes effect and newcomers become more isolated further marginalization may occur. By enforcing the language requirement, the Canadian government could be seen as nurturing the view that Non-English speaking groups are not welcome in Canada. Even the mere perception of these feelings could have a detrimental impact on Canada's long embraced commitment to multiculturalism. 


\section{Conclusions and Ideas for Future Research}

This essay has outlined three potential impacts of the new language requirement in Canada. The potential impacts included an increase in economic benefit for Canada by virtue of obtaining English-ready immigrants, a change in the ethnic backgrounds of immigrants, and an increase in the power and influence of the host population. Each one of these potential impacts represents an opportunity and a need for further research. It is important to note again that this essay did not address what the new language requirement means for French speaking immigrants or the French speaking host population. Because the number of English speakers in the world is greater than those who speak French, the Canadian English requirement is likely to have a more significant impact on Canada and its immigration policies. Separate research should be done to investigate what impact the French language proficiency requirement may have on French speaking immigrants and the Canadian French host population. With so many French speaking nations located in Africa, Canada could see an increase in immigrants from African nations. As European countries also shift away from immigration policies which favor multiculturalism, they too have put into place new language proficiency requirements. While it is highly unlikely that Canada will ever completely abandon their policy of Multiculturalism, they are beginning to redefine what being multicultural means in a practical sense. The fact that the new language requirement will have a disparate impact on visible minorities cannot be ignored. It is also possible that the language requirement is simply the tip of the iceberg in terms of greater restrictions on immigration in the future as Canada and many other countries continue to deal with unemployment challenges. It is possible these new restrictions could escalate tensions between various ethnic groups and the host population. In a more dramatic although not unprecedented scenario, feelings of superiority among the host population could lead to rising nationalism among right wing groups. Accordingly, isolated minority groups could resort to violent measures. It is fortunate that Canada's immigration policy has an inherent flexibility factor embedded in its current immigration system. This will make modifying acceptable exam scores a much simpler task then engaging in a complete overhaul of the policy. It is possible then that Canada can adjust requirements as needed in order to react to any unforeseen consequences of the new language requirement.

\section{References}

Black, D. (2013). Canada's immigration history one of discrimination and exclusion. TheStar.com. Retrieved from http://www.thestar.com/news/immigration/2013/02/15/canadas_immigration_history_one_of_discrimination_and_exclusion.tml

Canadian Multiculturalism Act (1988).R.S.C, 1988, C-18.7, c. 31. Retrieved from http://laws-lois.justice.gc.ca

CELPIP General (2012).CELPIP General - Free Sample Test.Retrieved from http://www.celpiptest.ca/free-sample-questions/

Citizenship and Immigration Canada. (2012a). Application for permanent residence: Federal skilled worker class (IMM 7000). Retrieved from http://www.cic.gc.ca/english/information/applications/guides/EG7TOC.asp

Citizenship and Immigration Canada (2012b).Annual Report on the Operation of the Canadia Multiculturalism Act 2010-2011. Retrieved from http://www.cic.gc.ca/english/resources/publications/multi-report2011/index.asp

Citizenship and Immigration Canada (2012c).News Release - Minister Kenney announces new language rules for citizenship applicants. Retrieved from http://www.cic.gc.ca/english/department/media/releases/2012/2012-09-28.asp

Citizenship and Immigration Canada (2012d).Canadian multiculturalism: an inclusive citizenship. Retrieved from http://www.cic.gc.ca/english/multiculturalism/citizenship.asp

Citizenship and Immigration Canada (2012e).Backgrounder - New minimum language requirements for immigrants under the Provincial Nominee Program. Retrieved from http://www.cic.gc.ca/english/department/media/backgrounders/2012/2012-0411.asp

Citizen and Immigration Canada (2011). Evaluation of the Language Instruction for Newcomers to Canada (LINC) Program. Retrieved from http://www.cic.gc.ca/english/resources/evaluation/linc/2010/summary-findings.asp\#a3

Citizen and Immigration Canada (2010). Facts and figures 2010 - Immigration overview:Permanent and temporary residents (Canada Permanent residents by source country). Retrieved from http://www.cic.gc.ca/english/resources/statistics/ facts2010/permanent/10.asp

Citizenship and Immigration Canada (2004).Citizenship and Immigration Canada enhanced language training initiative. Retrieved from http://www.cic.gc.ca/english/department/media/backgrounders/2004/2004-05-07.asp

Citizen and Immigration Canada (1996). Citizen and Immigration Statistics Archives 1966 - 1996. Retrieved from http://epe.lacbac.gc.ca/100/202/301/immigration_statistics-ef/index.html

Freisen, J. (2012a). Why Canada needs a flood of immigrants. The Globe and Mail. Retrieved from http://www.theglobeandmail.com/news/national/time-to-lead/why-canada-needs-a-flood-of-immigrants/article2423585

Freisen, J. (2012b). Canada to raise language bar.The Guardian. Retrieved from http://www.guardian.co.uk/education/ 2012/jun/19/canada-to-raise-language-bar

Green, A. \& Green, D. (2004). The goals of Canada's immigration policy: a historical perspective. Canadian Journal of Urban Research, $13(1), 102-139$. 
Immigration and Refugee Protection Regulations (2012). SOR 2002-227. Retrieved from http:/llaws-lois.justice.gc.ca

Kymlicka, W. (2012). Multiculturalism: Success, failure, and the future. Transatlantic Council on Migration.Retrieved from http://www.migrationpolicy.org/pubs/Multiculturalism.pdf

Li, P. S. (2001). The racial subtext in canada's immigration discourse. Journal of International Migration and Integration, 2(1), 77-97. doi: 10.1007/s12134-001-1020-1

Multiculturalism in Canada: one nation or many? (2006, November).The Economist. Retrieved from http://www.economist.com/node/ 8173164

Rodríguez-garcía, D. (2010). Beyond assimilation and multiculturalism: A critical review of the debate on managing diversity. Journal of International Migration and Integration, 11(3), 251-271. doi: 10.1007/s12134-010-0140-x

Strait, Patricia B., (2012) "When Societies Collide Part Three: Finding the Best Fit Immigration Model."The International Journal of Interdisciplinary Global Studies. Vol. N. TBA.

Tamburri, R. (1998, Apr 01). Canadians clash over cost of diversity plan would limit immigration to english, frenchspeakers. Wall Street Journal, pp. 1-A15. Retrieved from http://search.proquest.com/docview/398668946?accountid=14731 